\title{
Creating entrepreneurial employees in traditional service sectors
}

\section{The role of coaching and self-efficacy}

\author{
Ingrid Wakkee • Tom Elfring • Sylvia Monaghan
}

\begin{abstract}
Increasingly companies seek to enhance employee entrepreneurial behaviour. In this study we explore how coaching first reduces role conflicts associated with acting entrepreneurial and at the same time improving efficiency and reducing failure and secondly increases the entrepreneurial self-efficacy of employees. Building on previous conceptual and empirical studies on intrapreneurship, social psychology and human resource management we formulate several hypotheses concerning the relationship between self-efficacy, coaching and entrepreneurial behaviour of account managers that are tested in the context of a large service organization operating in the financial sector. In doing so we confirm and extend our insights on entrepreneurial behaviour in existing companies.
\end{abstract}

Keywords Intrapreneurship - Entrepreneurial behaviour - Self-efficacy · Role conflict · Coaching

\footnotetext{
I. Wakkee $(\bowtie) \cdot$ T. Elfring

Faculty of Social Sciences, VU University Amsterdam, De Boelelaan 1081, 1081 HV Amsterdam, The Netherlands

e-mail: iam.wakkee@fsw.vu.nl

I. Wakkee

Center for Innovation and Sustainable Entrepreneurship, VU University Amsterdam, Amsterdam, The Netherlands

T. Elfring

Faculty of Economics and Business Administration, VU University Amsterdam, Amsterdam, The Netherlands 


\section{Introduction}

Increasingly, mature companies are searching for ways to remain or become intrapreneurial and to enhance the entrepreneurial behaviour of their individual employees. This is not at all surprising, considering that the corporate landscape has become increasingly focused on strategic renewal (Guth and Ginsberg 1990), innovativeness and international competition (Brazeal and Hebert 1999). Indeed previous studies show that intrapreneurship (entrepreneurial behaviour within existing organisations) has a positive effect on the financial performance of organisations, especially in the long run (e.g. Zahra 1991; Stopford and Baden-Fuller 1994; Zahra and Covin 1995).

Despite considerable attention for intrapreneurship in the scientific and popular literature since the mid nineteen eighties we still do not fully understand how companies can enhance their level of intrapreneurship and take full advantage of its benefits (Zahra et al. 1999a, Mair 2005). One of the emerging issues is to identify the critical roles at different managerial levels in the corporate entrepreneurship process in order to improve our understanding why individuals decide to act entrepreneurially (Dess et al. 2003). In general, previous studies agree on the critical role of middle managers in providing support to operational managers to behave entrepreneurially (Kuratko et al. 2004). However, many issues remain unresolved (Dess et al. 2003). One of them is the role of coaching by middle level managers and its effect on entrepreneurial behaviour of operational managers.

Some evidence does suggest that coaching by managers might play an important role in improving employee entrepreneurial behaviour (e.g. Kelley et al. 2005; Mair 2005). Through coaching, managers provide their employees with access to resources and expertise, they can use their network and status to act as brokers to other parts of the organisation and they can stimulate their employees to reflect on how they can balance their emerging role of intrapreneur with potentially conflicting roles related to improving efficiency of existing business operations. Or in other words: coaching helps intrapreneurs "make sense" of what it takes to perform entrepreneurial tasks. It helps employees in recognising and reducing their insecurities with respect to their entrepreneurial behaviour (Chen et al. 1998) and is also of value in dealing with potential role conflict. Thus coaching by middle managers may enhance entrepreneurial behaviour of operational managers in two ways. First, we agree with Mair (2005) who claims that people can learn to improve their perceptions of self-efficacy and that programs aimed that changing behaviour may be an excellent tool for top management to enhance the level of intrapreneurship in their firm. Self-efficacy therefore seems to be an important explanatory variable when it comes to understanding the relationship between coaching and employee entrepreneurial behaviour. Secondly, increasing emphasis on entrepreneurial behaviour in large organizations creates ambiguity about role expectations at various management levels (Floyd and Lane 2000). In particular, operational managers may be confronted with role conflict, as there is no consensus about the degree in which they should engage in experimenting and opportunity seeking behaviour in combination with their traditional roles in improving efficiency in existing business practices. Coaching may help to reduce the negative implications related to role conflict. 
One of the important prerequisites for the existence of the described relationship is that managers are capable of coaching their employees in the right way and that employees perceive this coaching as being useful for achieving the desired ends. This might not always be the case; previous studies show that managers believe their coaching skills to be good, while employees perceive their manager's capacities in this area less well developed (e.g. ABN AMRO internal report 2005).

This study seeks to contribute to our understanding of how coaching by middle managers can enhance the entrepreneurial behaviour of operational managers in existing companies and thus increase the level of employee entrepreneurial behaviour and consequently the level of intrapreneurship of firms as a whole. To this end we explore how coaching, first may reduce role conflict among operational managers and secondly, can lead to enhancing their self-efficacy, which ultimately leads to increased employee entrepreneurial behaviour. We address the call to examine critical roles at different managerial levels and by combining insights from social psychology on entrepreneurial self-efficacy (Bandura 1997; Echols and Neck 1998; Chen et al. 1998; Mair 2005) with research findings in human resource management on coaching (Burdett 1998; Kelley et al. 2005; Popper and Lipshitz 1992), we are able to confirm and extend our knowledge on intrapreneurship and entrepreneurial behaviour.

\section{Theoretical framework and hypotheses}

\section{Intrapreneurship}

The concept of intrapreneurship - entrepreneurship within existing organisationshas been evolving for more than 30 years, though it seems to have gained momentum since the 1990s. Many authors have conceptualized intrapreneurship as encompassing organisational sanctions and resource commitments for the purpose of generating, developing and implementing innovative ideas and activities in the form of product, process and organisational innovations (Burgelman 1984; Kanter 1985, Damanpour 1991; Stopford and Baden-Fuller 1994). This is very much in line with descriptions by Schumpeter (1934) who states "Intrapreneurship consists of doing things that are not generally done in the ordinary course of business routine". According to Guth and Ginsberg (1990) the concept intrapreneurship refers to both the creation of new ventures within existing organisations and the transformation of existing organisations through innovation and strategic renewal and may be internally or externally oriented (Zahra 1999b). Intrapreneurship takes place at both the level of the organisation and at the level of the individual employees (Mair 2005). In the remainder of this paper we will differentiate between these two levels by using the label intrapreneurship for the organisational level and entrepreneurial behaviour for the individual level. At both levels, the pursuit of opportunities to create value is central (Stevenson and Jarillo 1990). At the organisational level the multidimensional construct Entrepreneurial Orientation (EO) is used most frequently to describe what this actually entails (Miller 1983; Covin and Slevin 1991; Lumpkin and Dess 1996; Brown et al. 2001). Typically, EO is perceived as consisting of three components, risk taking, innovativeness and proactiveness, which independently 
vary in strength and effect on organisational performance. Pro-activeness is the process of acting in anticipation of future needs, changes and challenges that can lead to new opportunities (Lumpkin and Dess 1996). Risk-taking is defined as venturing into unknown territory or circumstances without knowing what the results will be (Covin and Slevin 1991). Finally, innovativeness reflects the drive to deal with activities that result in new ideas and with experiments that may lead to new processes, products and services (Lyon et al. 2000).

\section{Employee entrepreneurial behaviour and self-efficacy}

Stimulating intrapreneurship is not an easy task and it is not something that can be achieved overnight. Rather becoming more intrapreneurial should be considered a learning process (Kanter 1985; Stevenson and Jarillo 1990; Hayton 2005) Earlier studies on how existing organization could become or remain intrapreneurial originally focused on the role of (top) managers as these were seen a so called corporate entrepreneurs. However in recent years attention has shifted to the role of employees as well as managers. Today "there is continually a need for organizational renewal, innovation, constructive risk taking, and the conceptualization and pursuit of new opportunities, a pursuit that often goes beyond the efforts of one key manager" (Miller 1983). Indeed due to factors such as increased competition and rapid innovation cycles, increasing mistrust of traditional bureaucratic organizing methods and higher skills levels of employees, it is simply not enough to leave entrepreneurship to the higher echelons of the organisation (Kuratko and Hodgetts 2003).

Enhancing entrepreneurial behaviour of individual employees throughout the organization is however not an easy task, especially when employees have been working for an organisation for a longer period and were always accountable for efficiency and effectiveness rather than for entrepreneurial behaviour. It may be difficult for such employees if they are suddenly exposed to an environment that is highly dynamic, complex and uncertain and in which they face the need to quickly choose among multiple competing courses of action, especially when there is insufficient information to decide on purely rational grounds (Busenitz and Barney 1997).

A large number of variables may influence the extent to which employees are able or can learn entrepreneurial behaviour. Previous research into demographic and psychological factors has remained inclusive (McClelland 1961; Brockhaus 1980). In addition, psychological variables are relatively stable over time and difficult to influence. If we want to enhance entrepreneurial behaviour knowledge of such psychological traits might only be taken into consideration when hiring or promoting people but will not help managers in dealing with their current employees and helping them to become more entrepreneurial. As a result, more recently scholars (Chen et al. 1998; Shook et al. 2003) have looked into the effects of cognitive aspects of entrepreneurial behaviour. Cognitive factors refer to patterns of thought and processing information and decision making by individuals. Shane and Venkataraman (2000) argue that gaining insight into how individuals process information cues may be key to understanding how, why and when individuals display more or less entrepreneurial behaviour. Main benefit of this approach is that cognitive factors, unlike demographics and psychological factors can be influenced and therefore allow for managerial intervention. 
In the context of new venture creation, cognitive factors such as entrepreneurial alertness, or the ability to notice without search, have received most attention (Kirzner 1979, 1997; Shane and Venkataraman 2000). Other factors that have been associated with entrepreneurship in both new and existing factors include decision making (Gartner 1985, 1988), 'counterfactual thinking and regret', 'affect infusion', 'self-serving bias', 'planning fallacy' en 'self-justification' (Baron 1998); emotional factors such as 'self-monitoring' and 'empathy' (Mair 2005) and finally self-efficacy (Bandura 1977; Shook et al. 2003). Self-efficacy is a concept developed by Bandura (1977) as part of his social learning theory. McShane and Von Glinow (2003) state that self-efficacy is "A person's belief that he or she has the ability, motivation, and resources to complete a task successfully". Important in this context is that selfefficacy is related to specific areas or contexts: for instance a student may have high level of self-efficacy regarding written exams but a low level of self-efficacy regarding writing a thesis. The reason for this seems to be that the level of selfefficacy is largely dependent on the person's previous experiences with reaching goals and dealing with challenges in these areas. Individuals with a high level of self-efficacy will initiate and perform new tasks at a much higher level than individual with lower levels of self-efficacy. Bandura (1977) and Wood and Bandura (1989) showed that self-efficacy is the most effective predictor of performance through directing interests, motivation and perseverance. The level of self-efficacy can thus be seen as a predictor of the effort invested in a particular task or activity which will clearly influence its outcome (Gist and Mitchell 1992; Choi et al. 2003). Stajkovic and Luthans (1998) showed just how strong this relationship actually is: in their study the level of self-efficacy explains $28 \%$ of the increase in performance, compared to $10.39 \%$ being explained by goal setting', $13.6 \%$ by 'feedback interventions' and $17 \%$ by changes in organisational behaviour'.

According to the social learning theory there is a reciprocal connection between cognition, behaviour and environment. Each of these variables affects and is affected by the other two variables. The notion of reciprocity is important for understanding self-efficacy. Performance and results are not only the effect of self-efficacy by they are also determinants by providing feedback which is used to evaluate and adapt the level of self-efficacy (Chen et al. 1998). Several authors have focused on selfefficacy in relation to entrepreneurship (Boyd and Vozikis 1994; Krueger and Brazeal 1994). Based on empirical investigations they concluded that Entrepreneurial Self-Efficacy (ESE) is an important variable explaining both the strength of entrepreneurial intentions and the likelihood of translating these intentions into entrepreneurial activities. Similarly, Krueger and Brazeal (1994) provided evidence of ESE being one of the main prerequisites of entrepreneurial behaviour. Shook et al. (2003) studied the behaviour of entrepreneurs (entrepreneurial intent, opportunity search and discovery, decision to exploit by new venture creation and opportunity exploitation activities) in relation to self-efficacy. They concluded that perceived self-efficacy regarding entrepreneurship has a positive influence on the development of entrepreneurial intent and behaviour and that it mediates the relationship between entrepreneurial initiatives and entrepreneurial behaviour through new venture creation. Similarly, Mair (2005) recently found that self-efficacy also serves as a strong indicator for entrepreneurial behaviour within existing organisations. Based on these findings we formulate the first hypothesis. 
H1 Entrepreneurial self-efficacy has a positive effect on entrepreneurial behaviour.

\section{Coaching, self-efficacy and entrepreneurial behaviour}

Self-efficacy cannot be enforced upon someone; an individual has to develop it personally (Hudson 1999). Yet, because self-efficacy is dependent on previous experiences and learning it is not surprising that many training programs and organisational chain programs focus on enhancing employee self-efficacy (Malone 2001). According to Popper and Lipshitz (1992), short term learning experiences and training programs such as workshops or lectures will not lead to sufficient enhancement of self-efficacy. In order to achieve that continuous learning is needed. Coaching could offer such a continuous learning environment and may therefore allow for development, internalisation of feelings of control and success and consequently on increased levels of employee self-efficacy. The stronger the trustrelationship between coach and trainee will become, the better trainees will be able to understand and enhance their own self-efficacy (Malone 2001).

In general, we can distinguish between four types of coaching: (1) Coaching in relation to learning; (2) coaching in relation to developing competencies; (3) coaching in relation to improving performance and (4) coaching in relation to personal growth/development and change. The different definitions that we can find in the literature typically reflect only one or two of these dimensions of coaching (e. g. Witherspoon and White 1996; Parsloe and Wray 2000; Zeus and Skiffington 2002; Greene and Grant 2003). A popular definition that is sufficiently broad is that of Kilburg (1996) who states that coaching is a helping relationship between a client (who has managerial authority and responsibility) and a coach who uses a wide variety of behavioural techniques and methods to help the client achieve a mutually identified set of goals to improve his or her professional performance and personal satisfaction and consequently to improve the effectiveness of the client's organisation within a formally defined coaching agreement. The main drawback of this definition however is its focus on the formal relationship or agreement between client and coach, which may be external to the organisation, rather than the daily informal relationship between an employee and a manager. Therefore, in this study we define coaching as 'a process of empowering employees to exceed prior levels of performance' (Burdett 1998; Evered and Selman 1989; Hargrove 1995). Coaching encompasses a set of behavioural activities and can take two basic forms: (1) the prescribing paradigm in which a coach directs, controls, and prescribes the employee's behaviour and (2) the empowerment paradigm in which a coach develops a learning environment and process that allows the employee to learn and develop competencies (Ellinger and Bostrom 1999). Because of the nature of entrepreneurial behaviour, which is more directed at taking initiatives than following orders, the second paradigm is most applicable in this study.

So, how does coaching lead to enhancing self-efficacy? In general, it seems that coaching should include the transfer of knowledge and empowering an individual to accomplishing certain responsibilities and goals (Popper and Lipshitz 1992). Empowerment can be seen as direct way of enhancing the perceived self-efficacy of the trainee so that he or she believes it is possible to reach certain goals. As explained previously, the level of self-efficacy is largely 
determined by previous experiences: when an individual thinks to have performed these tasks successfully this individual with have a higher level of self-efficacy than when he or she experienced a failure. From the above we formulate the following hypothesis:

H2 Coaching by managers has a positive effect on the level of employee selfefficacy.

Some authors have suggested that there could be a direct relationship between coaching and the level of employee entrepreneurial behaviour. Kelley et al. (2005) provide several arguments for this proposed relationship. First, through coaching managers provide the employee with access to other resources and expertise that can help the employee develop new ideas. Second, managers usually have extended networks and social status within the organisation that can facilitate the creation of co-operation across different organisational departments. This brokerage function can lead to the creation of new combinations of information, resources and processes and thus to the recognition of new opportunities, which are central in entrepreneurship (Granovetter 1973). Third, coaches can ensure that their employees are more aware of the importance of entrepreneurial behaviour by regularly discussing the topic. This awareness in turn can influence actual behaviour of the employees by raising the alertness (Kirzner 1979, 1997). Particularly, coaches can guide their employees towards a better focus on critical organisational issues and processes. In this way they can stimulate employees to consider what activities would lead to value creation rather generating new ideas at random. In addition to these reasons the influence of goal setting should also be taken into consideration. One of the most important tasks of coaches is setting goals and making agreements with the employees. If these goals are directed at entrepreneurial behaviour, this will challenge the employee and it seems likely that the employee will indeed exhibit increased entrepreneurial behaviour. As argued, increasing awareness of the importance of entrepreneurial behaviour of operational managers creates a potential role conflict. New roles related to opportunity seeking may be difficult to reconcile with their roles to ensure an optimal efficiency of current activities. Uncertainty concerning what tasks and roles have priority leads to role conflict (Floyd and Lane 2000). The operational manager has to balance the role of improving efficiency with experimenting and other roles related to the discovery of opportunities. Coaching can reduce this ambiguity and tension concerning these potentially conflicting roles and thus positively affects entrepreneurial behaviour of operational managers directly in a second way.

Therefore we the final hypotheses is formulated as:

H3 Coaching by managers has a direct positive effect on employee entrepreneurial behaviour.

Combining the theoretical findings and hypotheses as presented in the previous paragraphs we developed a conceptual model displaying the proposed relationships between coaching, self-efficacy and employee entrepreneurial behaviour. This model is graphically displayed in Fig. 1. 


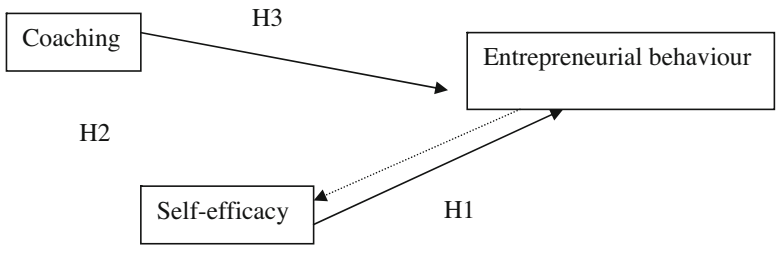

Fig. 1 Conceptual model

\section{Method}

The purpose of our empirical investigation is to test the proposed relationships between coaching, self-efficacy and employee level behaviour. A secondary goal is to gain insight in to how managers and employees perceive the managerial coaching capabilities and employee entrepreneurial behaviour.

\section{Instrument}

The empirical investigation will take place through a cross-sectional survey. This instrument consisted of one questionnaire for a sample of employees and one for managers working at 31 branches/offices of a Dutch Multinational active in the financial services sector. The company employs more than 100,000 full time equivalents worldwide of which 521 work at the local offices in the region of Amsterdam, the Netherlands ${ }^{1}$ where this study takes place. The firm has historically been hierarchically organized with very few possibilities for lower and middle echelon managers and employees to participate in strategy development and entrepreneurial behaviour (Segal-Horn 1998: 435). In the last decade, however the firm has made significant steps in reorganizing the firm to become more organic and innovative. Since 2003, personal leadership, corporate culture and entrepreneurship have become key concepts or values in the organisational strategy.

To ensure the validity of our instrument we used existing measures where possible, though translating the items from English to Dutch. In this process we made several changes to the original questions to reflect the local context and make the instrument fit for the local culture. To determine the internal consistency of our constructs we used factor analysis and Cronbach's alpha to test unidimensionality and inter-item reliability (Carmines and Zeller 1979).

In order to verify to what extent the questionnaire satisfied the requirements and constraints a pilot test was executed consisting of a peer briefing and members checks. The pilot questionnaire was discussed with three university professors and

\footnotetext{
${ }^{1}$ The principal investigator of this study has been employed at this organisation for several years with facilitated access, and possibly increased the response rate while at the same time allowing us to create instruments that fitted the selected context accurately.
} 
with the experts working at the bank (one HR manager, one higher echelon management, and two lower echelon management). Next, we tested the questionnaire amongst 3 managers and 27 employees respectively asking each of them to provide us with comments and suggestions for improvements.

Rather than sending our questionnaire to all employees working at the selected offices we drew a stratified sample to ensure equal (or at least comparable) representation of the 31 branches. In drawing this sample we considered the total number of employees at the individual branches relative to the total population of employees in the region thereby enhancing population validity. We did however include all managers in our sample in order to generate a data set that is large enough to conduct meaningful statistical analyses.

All questionnaires were sent by internal mail. To increase the employee-response level a letter of recommendation written by an important CEO was included in the questionnaire along with an explanatory letter in which we explained the purpose of the research. Further along with the manager-questionnaire we included a request urge their employees to participate during the next staff meeting.

\section{Sample and response}

In total we sent the questionnaire to 56 managers and 521 employees. To ensure anonymity the questionnaires were numbered. Exactly 1 month after sending the original questionnaire, e-mails were sent to the non-respondents with a reminder and request to participate. To maximize the response rate, we included the questionnaire as an attachment together with an invitation to send the completed questionnaire by e-mail. As we reached response levels of $59(n=307)$ and $82(n=46)$ per cent for employees and managers respectively with at least one manager representing each office, after this first reminder, it was deemed unnecessary to send out a second reminder. Non-response analysis (see also Table 1) showed a lack of interest due of the large number of request for participation was the principal reason for nonresponse followed by lack of time and absence.

\section{Variables and measures}

The employee- questionnaire consists of four parts that contain items to measure entrepreneurial behaviour, self-efficacy, coaching and background. These variables are measured at the individual level. The manager questionnaire has three parts: entrepreneurial behaviour, coaching and background. In this questionnaire we omitted questions about self-efficacy as we considered it impossible for managers to

Table 1 Non-response analysis

\begin{tabular}{llll}
\hline Non-response & Large office (\%) & Middle size office (\%) & Small office (\%) \\
\hline Not interested, research topic & 0 & 0 & 0 \\
$\begin{array}{l}\text { Not interested too many requests for } \\
\quad 50\end{array}$ & 25 & 37.5 & 50 \\
$\quad$ participation in research & & \\
Lack of Time & 25 & 37.5 & 0 \\
Absence (e.g. pregnancy or illness) & 50 \\
\hline
\end{tabular}


judge the level of self-efficacy of their employees and as measure their own selfefficacy is beyond the scope of this study and irrelevant for testing our hypotheses. In this manager-questionnaire, entrepreneurial behaviour is measured at the group level (all the manager's employees) while coaching is measured at the individual level (reflecting the manager's own personal coaching capabilities).

\section{Dependent variable}

The dependent variable in this study is the (operational managers') level of entrepreneurial behaviour. To measure this we use the construct developed by Stull and Singh (2005). This construct breaks entrepreneurial behaviour down into three dimensions that may independently vary in strength and effect, namely proactiveness, risk-taking and innovativeness. Each of these dimensions is measured using five items on a five point Likert scale ranging from $1=$ completely agree and $5=$ completely disagree. In the original study strong Cronbach's alpha were obtained of 0.76 , and factor analysis showed high and uniform loading on three dimensions as expected. To verify if these dimensions would also apply to entrepreneurial behaviour at a bank, three key informants at the bank were asked, in a miniinterview, to mention as many characteristics of entrepreneurial behaviour at the bank as they could. The findings of these interviews are displayed in Table 2.

As shown, no significant deviations were found between the observations from these informants in relation to the theory. Consequently we decided to use the Stull and Singh (2005) measure here without further changes. To measure the level of EO we first summed the scores for the individual items related to the three dimensions and then summed these scores for innovativeness, proactiveness and risk-taking. Factor analysis based on obtained data set showed that the measure is reliable with a Cronbach's alpha of 0.695 yet, the items do not load onto the three dimensions as expected.

For the manager-questionnaire we used the same items but they were rephrased to measure the level of entrepreneurial behaviour of the manager's team. For instance in the employee questionnaire we asked the respondents to react to the following statement: ('When I am working,...) I take the initiative to initiate new projects'. In the manager questionnaire this same question is rephrased as follows: ('While at work,...) my team takes the initiative to initiate new projects'. Next, the manager is asked to respond to this statement by indicating if many or few of the team members do this. For the responding managers at the bank we obtained a Cronbach's alpha of 0.757. Again, the items did not load on the three dimensions as expected.

Table 2 Findings from mini-interview

Could you mention to me, as many characteristics that describe entrepreneurial behaviour at the bank as you can? 


\section{Independent variables}

The independent variables in this study are coaching and self-efficacy of which the latter is only measured in the employee-questionnaire). To measure self-efficacy we used the New General Self-Efficacy Scale (NGSE) developed and tested by Chen et al. (2001). This scale consists of eight items and the reliability was measured at three moments in time each yielding good internal consistency and Cronbach's alpha's of respectively $0.85,0.88$ and 0.86 . The items are listed as statements and the respondents were asked to indicate the extent of their agreement with these statements on a five point Liker scale. Because in this research we are not searching for general self-efficacy, but self-efficacy in relation to entrepreneurial behaviour, the respondents were asked to consider the statements in relation to entrepreneurial behaviour. Our own factor analysis showed that the measure is highly unidimensional, i.e. all items loaded on a single component and we obtained a Cronbach's alpha of 0.84 .

Coaching was measured using a reduced version of an existing questionnaire developed by Millward Brown (2005) that was used in an earlier internal research at the organisation where this research was conducted in 2004 and 2005. The items included in this questionnaire are similar to those used by other authors. The most important dimensions measured with these items include: setting agreements and providing feedback. The employee-questionnaire included seven statements about the coaching capacities of their manager, e.g. my manager has made concrete agreements with me regarding coaching. The respondents were asked to indicate the number that best described their level of agreement with this statement. For the manager-questionnaire we used almost the same statements and approach, yet asking the respondent to judge his or her own coaching behaviour. Factor analysis showed that both measures were unidimensional and had high levels of inter-item reliability $(\alpha=0.837$ and 0.792 for employees and managers respectively).

\section{Control variables}

We also included a small number of control variables to determine if differences in the level of entrepreneurial behaviour can be contributed to personal characteristics. In particular we included the level of education, the number of years working for the company, the job and the job level (position in the hierarchy). In the managerquestionnaire we included questions regarding level of education, the number of years working for the company, years in the current position, management experience in the previous position, job, and the number of employees supervised.

\section{Results}

Description of the data set

Before testing our hypotheses we first conducted an exploratory investigation of our data set. The findings are summarized in Table 3. The second column in Table 3 shows the findings for the operational managers, and in the third column the findings 
Table 3 Descriptives of the data set

\begin{tabular}{|c|c|c|c|c|c|}
\hline \multirow[t]{3}{*}{ Variable } & \multirow[t]{3}{*}{ Answer category } & \multirow{2}{*}{\multicolumn{2}{|c|}{$\begin{array}{l}\text { Employees } \\
(N=298)\end{array}$}} & \multirow{2}{*}{\multicolumn{2}{|c|}{$\frac{\text { Managers }}{(N=42)}$}} \\
\hline & & & & & \\
\hline & & $N$ & Percent & $N$ & Percent \\
\hline \multirow[t]{5}{*}{ Level of education } & Lower secondary (VMBO/LBO/MAVO) & 28 & 9.4 & 0 & 0 \\
\hline & $\begin{array}{l}\text { High levels secondary education } \\
\text { (HAVO/VWO) }\end{array}$ & 66 & 22.1 & 10 & 23.8 \\
\hline & Vocational (MBO) & 53 & 17.8 & 5 & 11.9 \\
\hline & Higher vocational (HBO) & 128 & 43.0 & 20 & 47.6 \\
\hline & Academic (WO) & 23 & 7.7 & 7 & 16.7 \\
\hline \multirow[t]{3}{*}{ Years working for the company } & $<2$ years & 33 & 11.1 & 1 & 2.4 \\
\hline & $>2<15$ years & 141 & 47.5 & 23 & 54.8 \\
\hline & $>15$ years & 123 & 41.4 & 18 & 42.9 \\
\hline \multirow[t]{3}{*}{ Number of years in function } & $<2$ years & & & 22 & 52.4 \\
\hline & $>2<5$ years & & & 19 & 45.2 \\
\hline & $>5$ years & & & 1 & 2.4 \\
\hline \multirow[t]{2}{*}{ Function level } & $1-6$ & 96 & 32.4 & & \\
\hline & $7-10$ & 192 & 64.9 & & \\
\hline \multirow[t]{6}{*}{ Function } & Assistant & 101 & 34 & & \\
\hline & Account Manager & 191 & 64.3 & & \\
\hline & Manager & & & 31 & 73.8 \\
\hline & Team Leader & & & 11 & 26.2 \\
\hline & Other & 5 & 1.7 & & \\
\hline & $10+$ & 8 & 2.7 & & \\
\hline \multirow[t]{2}{*}{ Previous function } & Managerial & & & 24 & 57.1 \\
\hline & Non-managerial & & & 18 & 42.9 \\
\hline
\end{tabular}

from the middle managers are shown. The findings show that about $50 \%$ of the operational managers and $60 \%$ of the middle managers have a higher-level education (higher vocational or academic). Only a small group of the response came to work for the company less than 2 years (11.1 and 2.4\% respectively for operational managers and middle managers). More than $40 \%$ of both the operational and middle managers even have been employed at the organization for more than 15 years. Most middle managers have less than 2 years experience in their current position and only one has more than 5 years experience. Yet, because in $57 \%$ of the cases their previous function was also a managerial position we can nevertheless assume that most managers are relatively experienced.

To determine whether the sample is indeed an independent sample, we conducted an ANOVA analysis. After all, we could imagine that within each office homogeneity of variance (Field 2005) would exist and that the offices would be different. If this were the case our sample would actually be 31 (offices) rather than 298 (operational managers). However, the ANOVA showed that our sample is indeed an independent sample. The group means with respect to entrepreneurial behaviour of operational managers in the different offices are not significantly different $[F(267,30)=1.366, p=0.103]$ and the same was found with respect to selfefficacy $[F(267,30)=1.404, p=0.085]$ and coaching $[F(266,30)=1.214, p=0.211)$. Consequently, our sample meets the criteria for independence needed to conduct correlation and regression analyses and for conducting $t$ tests and ANOVA to determine differences in means. 
Before conducting these tests we first explored the levels of the dimensions of entrepreneurial behaviour, self-efficacy and coaching capabilities using descriptive statistics. As can be seen in Table 4 most operational managers do not consider themselves to be very risk-taking, $(3,13=$ neutral to somewhat disagree), while they rate their own level of proactiveness and innovativeness as somewhat better $(2,43$; $246=$ neutral to somewhat agree). When asked to provide additional remarks at the and of the questionnaire several employees indicated that in their mind they did have an entrepreneurial personality but that the nature of the organization (sector, culture, hierarchy, head quarter control) did not allow them to exploit this entrepreneurial character to the full. This perspective is reflected in the level of entrepreneurial selfefficacy that was judged relatively positively $(M=1.98, \mathrm{SD}=0.407$.). Regarding coaching the findings suggest a mildly positive perception but considerable variation within the sample $(M=2,71 ; \mathrm{SD}=0.737)$.

T-tests and ANOVA analyses further revealed that highly educated operational managers (higher vocational training or academic) exhibit higher levels of entrepreneurial behaviour than operational managers with lower levels of education and that more experienced operational managers are more entrepreneurial than their less experienced colleagues $[F(294,3)=3.070, p=0.028]$. Alternatively, there is no significant difference between account managers and assistants and between account managers in the private and commercial sector in terms of entrepreneurial orientation.

When looking at the middle managers we see that no significant difference can be observed when comparing the perception of high and low levels of education and when comparing team leaders with the other middle with respect to their coaching abilities or when comparing middle managers with longer or shorter work experience within the company $[F(38,2)=0.502, p=0.610]$ or within the same position $(38,2)=0.337, p=0.716$. Middle managers with previous managerial experience do perceive their coaching abilities as better than those without managerial experience in their previous position. Finally, a correlation analysis revealed that there is a significant negative relationship between the number of employees in a manager's team and the manager's perception of their own coach abilities. $r=-0.384, p<0.05$.

After that, we examined the relationship between the middle manager's perceptions of his or her team's entrepreneurial behaviour and the perception of these team members with regard to their own entrepreneurial behaviour using a paired sample $t$ test. We found that middle manager's perceive the level of entrepreneurial behaviour

Table 4 Exploratory information dependent and independent variables

\begin{tabular}{llllll}
\hline$N$ & Minimum & Maximum & Mean & SD & \\
\hline TOTRI & 298 & 2 & 5 & 3.13 & 0.500 \\
TOTPR & 298 & 1 & 4 & 2.43 & 0.529 \\
TOTINN & 298 & 1 & 4 & 2.46 & 0.570 \\
EEB & 298 & 1 & 4 & 2.68 & 0.368 \\
ESE & 298 & 1 & 4 & 1.98 & 0.407 \\
MCA & 298 & 1 & 5 & 2.71 & 0.737 \\
Valid $N$ & 298 & & & & \\
\hline
\end{tabular}


of their team to be slightly higher (2.63) than the employees rate their own abilities (2.69) but this difference is insignificant $[T(31)=-0.816, p=0.421$ (two-tailed, $p>0.050)$ ]. When comparing middle manager's and operational managers with respect to their perception of the middle manager's coaching abilities we found that middle manager's perceive their own abilities to be significantly higher (2.1014) than the operational managers do (2.7139) with $t(30)=-5.559, p<0.001$. Correlation analysis indicated that the higher the middle manager rates their own coaching abilities, the lower this ability is rated by their team members, yet this correlation is not significant $(r=-0.082, p=0.660)$. The findings for the $t$ tests and ANOVA analyses are summarized in Table 5.

\section{Hypothesis testing}

To test our hypotheses, we first used the data obtained from the employee-questionnaire to determine the relationships between our variables. Table 6 shows significant positive correlations between employee self-efficacy (ESE) and employee entrepreneurial behaviour (EEB) and between managerial coaching (MC) and employee entrepreneurial behaviour (EEB) and no significant correlation between managerial coaching (MC) and employee self-efficacy (ESE). Thus, the correlations provide some preliminary evidence that we can accept hypotheses 1 'Self-efficacy has a positive effect on entrepreneurial behaviour' and hypotheses 3 'Coaching has a positive effect on entrepreneurial behaviour'. The findings also suggest that we should reject hypotheses 2 'Coaching has a positive effect on self-efficacy' because the correlation is not significant. Because the literature suggests that learning capabilities and experience are a strong indications for the extent to which self-efficacy can be enhanced we decided to conduct a final analysis on the relationship between coaching and self-

Table $5 t$ Tests and ANOVA for employee entrepreneurial behaviour and managerial coaching

\begin{tabular}{|c|c|c|c|c|c|}
\hline Groups & Means & $t$ & $p$ value & ANOVA, $F$ & Correlation, $r$ \\
\hline High levels of education (E) & 2.6 & 3.790 & $0.001 * *$ & & \\
\hline Low levels of education (E) & 2.76 & & (two tailed) & & \\
\hline Account managers $(\mathrm{E})$ & 2.68 & 1.660 & $0.098 *$ & & \\
\hline Assistants (E) & 2.73 & & (two tailed) & & \\
\hline Private $(E)$ & 2.69 & 0.619 & 0.537 & & \\
\hline Commercial $(\mathrm{E})$ & 2.66 & & & & \\
\hline High levels of education (M) & 2.17 & 0.804 & 0.426 & & \\
\hline Low levels of education (M) & 2.03 & & & & \\
\hline Managers (M) & 2.07 & -0.166 & 0.869 & & \\
\hline Team leaders (M) & 2.10 & & & & \\
\hline Managerial experience (M) & 1.93 & -2.124 & $0.040 * *$ & & \\
\hline No managerial experience (M) & 2.28 & & (two-tailed) & & \\
\hline $\begin{array}{l}\text { More vs less company } \\
\text { experience (M) }\end{array}$ & & & 0.610 & $\begin{array}{c}F(38.2)= \\
0.502\end{array}$ & \\
\hline $\begin{array}{l}\text { More vs less experience in } \\
\text { same position }\end{array}$ & & & 0.716 & $\begin{array}{c}F(38.2)= \\
0.337\end{array}$ & \\
\hline Team size (coaching) (M) & & & $<0.05^{* *}$ & & -0.384 \\
\hline
\end{tabular}

* Significant at the $90 \%$ interval level

** Significant at the $95 \%$ interval level 
Table 6 Correlations between entrepreneurial behaviour, self-efficacy and coaching

\begin{tabular}{lll}
\hline & ESE & MC \\
\hline EEB & & $0.159^{\mathrm{a}}$ \\
Pearson correlation & $0.420^{\mathrm{a}}$ & 0.006 \\
Sig. (two-tailed) & 0.000 & 297 \\
$N$ & 298 & 0.019 \\
ESE & & 0.750 \\
Pearson correlation & & 297 \\
Sig. (two-tailed) & & \\
$N$ & & \\
\hline
\end{tabular}

${ }^{\text {a }}$ Correlation is significant at the 0.01 level (two-tailed)

efficacy including only those operational managers with higher vocational or academic levels of education and including only experienced operational managers. Yet, the correlation coefficient $(0.66 ; p=0.419 ; 0.045 ; p=0.620)$ indicated that even in these groups better coaching does not lead to increased self-efficacy in this organization.

To further test these hypotheses we conducted a stepwise-regression analysis based on the employee-data, for which the results are summarized in Tables 7 and 8. Model 1 includes only the independent variable ESE, in Model 2 both independent variables (ESE and MC) are included and in Model 3 the both the independent and the control variables were included. Because of the high levels of collinearity, 'experience' and 'function level' were removed from the model leaving level of 'education' as the sole control variable. We can observe that our independent variables explain 19.4\% additional variance (adjusted $R^{2}$ ) in the level of entrepreneurial behaviour of which $17.4 \%$ stems from self-efficacy. This means that almost $81 \%$ of the variance is explained by other factors (Table 8).

These findings indicate further support hypotheses 1 and 3, however it should be noted that the actual effect of coaching on entrepreneurial behaviour is very small. We already found that there was no significant correlation between coaching and self-efficacy, suggesting that hypothesis 2 should be rejected. A simple regression analysis confirmed that there was no direct relationship between these two factors.

Table 7 Regression analysis

\begin{tabular}{|c|c|c|c|c|c|c|}
\hline \multicolumn{7}{|c|}{ Coefficients $^{\mathrm{a}}$} \\
\hline \multicolumn{2}{|c|}{ Model } & \multicolumn{2}{|c|}{ Unstandardized coefficients } & \multirow{2}{*}{$\frac{\text { Standardized coefficients }}{\text { Beta }}$} & \multirow[t]{2}{*}{$T$} & \multirow[t]{2}{*}{ Sig. } \\
\hline & & $\mathrm{B}$ & SE & & & \\
\hline \multirow[t]{2}{*}{1} & (Constant) & 1.921 & 0.097 & & 19.815 & 0.000 \\
\hline & ESE & 0.381 & 0.048 & 0.420 & 7.954 & 0.000 \\
\hline \multirow[t]{3}{*}{2} & (Constant) & 1.722 & 0.118 & & 14.578 & 0.000 \\
\hline & ESE & 0.378 & 0.047 & 0.417 & 7.998 & 0.000 \\
\hline & $\mathrm{MC}$ & 0.075 & 0.026 & 0.151 & 2.891 & 0.004 \\
\hline \multirow[t]{4}{*}{3} & (Constant) & 1.819 & 0.124 & & 14.698 & 0.000 \\
\hline & ESE & 0.352 & 0.048 & 0.388 & 7.315 & 0.000 \\
\hline & $\mathrm{MC}$ & 0.076 & 0.026 & 0.153 & 2.950 & 0.003 \\
\hline & Education & -0.095 & 0.039 & -0.129 & -2.439 & 0.015 \\
\hline
\end{tabular}

\footnotetext{
${ }^{a}$ Dependent variable: EEB
} 
Table 8 Model summary

\begin{tabular}{lllll}
\hline Model & $R$ & $R^{2}$ & Adjusted $R^{2}$ & SE of the estimate \\
\hline 1 & $0.420^{\mathrm{a}}$ & 0.177 & 0.174 & 0.335 \\
2 & $0.446^{\mathrm{b}}$ & 0.199 & 0.194 & 0.331 \\
3 & $0.464^{\mathrm{c}}$ & 0.215 & 0.207 & 0.328 \\
\hline
\end{tabular}

\footnotetext{
${ }^{a}$ Predictors: (constant), ESE

${ }^{\mathrm{b}}$ Predictors: (constant), ESE, MC

${ }^{\mathrm{c}}$ Predictors: (constant), ESE, MC, experience
}

Although we thus had to reject the second hypothesis, we wondered if coaching would act as an mediation or interaction variable for the relationship between selfefficacy and entrepreneurial behaviour meaning that the effect of coaching on entrepreneurial behaviour would depend on the level of self-efficacy (for example only when the level of self-efficacy is high to begin with coaching would have a positive effect on entrepreneurial behaviour). Because the relationship between the dependent variable (EEB) and the independent variable (MC) is still significant at the $95 \%$ confidence level when the mediating variable (ESE) is included in the regression analysis (Model 2) technically there is no mediation and no interaction (Baron and Kenny 1986).

After having examined the operational manager data we turned to the middle manager-data and explored the relationship between the middle managers' perception of coaching and entrepreneurial behaviour of their operational managers. Therefore, we examined the correlation co-efficient for the coaching $(\mathrm{CM})$ and team level entrepreneurial orientation (TEB) based on the data set obtained from the middle managers. However, contrary to what the operational manager data suggest, we found that no significant correlation exists between coaching and entrepreneurial behaviour as perceived by middle managers [Pearson correlation, $-0.145(p>0.05$ at $0.365]$. When correlating coaching with the individual dimensions of entrepreneurial behaviour we found that coaching is significantly positively related with risk taking but not with proactiveness or innovativeness at the $95 \%$ interval level. This indicates that the perceived level of entrepreneurial behaviour of their team does not increase with a middle manager's self-perceived coaching capabilities. Consequently, based on the middle manager-data we can only partially accept hypotheses 3 (Table 9).

Table 9 Correlation coefficients for managers

\begin{tabular}{llllll}
\hline Correlations & \multicolumn{3}{l}{} \\
\hline & & Totris & Totpro & Totinno & Totcoa \\
\hline \multirow{2}{*}{ Totcoa } & Pearson correlation & $0.348^{*}$ & -0.281 & -0.226 & 1 \\
& Sig. (two-tailed) & 0.026 & 0.075 & 0.155 & 41 \\
\hline
\end{tabular}

*Correlation is significant at the 0.05 level (two-tailed) 


\section{Discussion and conclusions}

Despite considerable attention for intrapreneurship, we still do not fully understand how employees can become more entrepreneurial and thus how the level of entrepreneurial behaviour of complete organizations can be enhanced. Our empirical investigation showed that coaching and self-efficacy both had a significant positive effect on the level of entrepreneurial behaviour thereby supporting hypotheses 1 (Entrepreneurial self-efficacy has a positive effect on entrepreneurial behaviour) and H3 (Coaching by managers has a direct positive effect on employee entrepreneurial behaviour). This suggests that indeed both organisational and individual variables are important predictors of entrepreneurial behaviour. These findings are line with previous studies by e.g. Chen et al. (1998) who suggested that when a person believes he or she is capable of entrepreneurial behaviour this perception will be reflected in the actual level of this entrepreneurial behaviour and Kelly et al. (2005) who argued that employees benefit from the knowledge, expertise and networks provided by their coach in developing new ideas for entrepreneurial activities.

We could not find evidence for a relationship between coaching and self-efficacy. Thus we had to reject hypotheses 2 (Coaching by managers has a positive effect on the level of employee self-efficacy). There may be several explanations for the absence of a relationship between coaching and self-efficacy. The first reason could be that coaching in this organisation is not sufficiently targeted at enhancing entrepreneurial self-efficacy. As Popper and Lipshitz (1992) argued, coaching only leads to learning when it takes place on a continual basis, when coaching is limited to short periods of time or takes place on a ad hoc basis, employees will not develop the required level of self-efficacy. A successful experience could then by considered incidental luck rather than the effect of the coaching and learning that has been taking place. If this is the case in the surveyed company, coaching might have to take another form. Possibly top management would have to consider training their officelevel managers to focus more specifically on entrepreneurship. A second explanation for not finding a relationship could be that coaching is aimed sufficiently at entrepreneurship but that was only begun too recently to have real effects on selfefficacy and thus to influence entrepreneurial behaviour indirectly. Zahra and Covin (1995) already showed that significant time periods have to pass before increased levels of entrepreneurial behaviour have a significant observable effect on performance. Because the firm where this research was conducted only began to stimulate entrepreneurial behaviour recently it seems unlikely that such effects would be observable.

It has previously been suggested that that self-efficacy will only be enhanced in trust-relationships (Malone 2001). If coaching has not yet lead to a certain level of trust, this might explain why coaching has not yet lead to enhanced self-efficacy in the surveyed company. An indication for this might be that according to our findings no differences exist in relation to the perception of employees and managers with respect to management coaching, whereas previous research at the same organization did show such a difference existed (in the original study managers judged their own coaching capabilities better than the employees did).

This study contributes to the theory of intrapreneurship by studying the effects of coaching and self-efficacy on employee level entrepreneurial behaviour and by 
linking existing theories about entrepreneurial self-efficacy to the theory about coaching. The concepts of coaching and self-efficacy are interesting as they allow us to combine organizational and individual perspectives on entrepreneurial behaviour. In this study coaching can be seen as a macro-level or organisational predictor of entrepreneurial behaviour, self-efficacy as the micro-level or individual predictor. Consequently, we have addressed the call 'to further delineate the roles of all managerial levels in the corporate entrepreneurship process' (Kuratko et al. 2004: 711) and contributed to improve our understanding of the combined micro- and macro level effect on entrepreneurial behaviour.

This study has two key insights for managers. First it is important to foster selfefficacy by helping employees recognize what they can do, over what they cannot yet accomplish. Second, although our study has not yet shown the mechanisms by which coaching affects entrepreneurial behaviour, our findings show that coaching should be an important mechanism if employees are expected to become more entrepreneurial in their behaviour. We advice that in this coaching attention is particularly devoted to the reduction of role conflicts in relation to being entrepreneurial and accountable for efficiency and effectiveness.

\section{Limitations and needs for further research}

The direct effect of self-efficacy and coaching on the level of entrepreneurial behaviour in this organization seems promising and can serve as an example to other firms. Yet, it should be noted that like any study, our investigation has several limitation regarding their scope, and method. When looking at the scope of this study it is clear that we only incorporated a small number of variables to explain the level of entrepreneurial behaviour. As these variables only account for $17 \%$ of the total variance in the level of entrepreneurial behaviour it seems clear that other variables would need to be included in our model. Previous research has pointed a large number of potentially relevant variables such as organizational culture, sector of industry, previous experience and top management dedication. Further research should be targeted at developing and testing theoretical models in which these and other variables are connected to each other and to entrepreneurial behaviour. When asked to provide additional remarks at the and of the questionnaire several employees indicated that in their mind they did have an entrepreneurial personality but that the nature of the organization (sector, culture, hierarchy, head quarter control) did not allow them to exploit this entrepreneurial character to the full. Clearly exploring such relationships in future research seems worthwhile and will help us gain an even better understanding of how managers can enhance the entrepreneurial behaviour of their employees and the thus increase intrapreneurship throughout the firm. For now, managers should therefore be aware that they coach their employees in such a way that they both perceive themselves of being capable of entrepreneurial behaviour and so that they are not prevented by constraints in the organisation structure and culture.

An important limitation with respect to the method concerns the cross-sectional nature of this study that makes it difficult to establish causal relationships. Indeed, several previous studies have suggested that a positive relationship exists between 
self-efficacy and entrepreneurial behaviour while in other papers it was argued that entrepreneurial behaviour can also influence the level of self-efficacy. Although longitudinal studies would be necessary to establish a the proper time order, in a cross-sectional study like this, a causal relationship may only be assumed when three requirements have been met: statistical correlations, a proper time order can be established and observed relationships that cannot be linked to third variables. In this study the first criteria was met as was shown from the cross-tables and co-efficient correlations we generated with SPSS. We have tried to meet the second criterion by building on existing theoretical insights supporting the proposed causal relationships and from this we developed a conceptual model.

A final limitation concerns the fact that we only conducted this study in a single organisation and in a single country. Although there are several theoretical reasons why we expect that our findings can be generalised to other service-firms, particularly those that are active in the same financial sector, testing these hypotheses amongst a larger set of firms across industries and countries would be necessary to determine the actual generalisability of our findings.

Acknowledgements The authors want to thank the bank and its employees for providing ample cooperation and allowing us to collect data.

Open Access This article is distributed under the terms of the Creative Commons Attribution Noncommercial License which permits any noncommercial use, distribution, and reproduction in any medium, provided the original author(s) and source are credited.

\section{References}

ABN AMRO (2005). Twee-meting performance management. Amsterdam: Interne Communicatie BU NL.

Bandura, A. (1977). Self-efficacy: toward a unifying theory of behavioural change. Psychological Review, 84(2), 191-215.

Baron, R. A. (1998). Cognitive mechanisms in entrepreneurship: why and when entrepreneurs think differently then other people. Journal of Business Venturing, 13, 275-294.

Baron, R. M., \& Kenny, D. A. (1986). The moderator-mediator distinction in social psychological research: conceptual, strategic, and statistical considerations. Journal of Personality and Social Psychology, 51, 1173-1182.

Boyd, N. G., \& Vozikis, G. S. (1994). The influences of self-efficacy on the development of entrepreneurial intentions and actions. Entrepreneurship: Theory and Practice, 18, 63-90.

Brazeal, D. V., \& Hébert, T. T. (1999). The genesis of entrepreneurship. Entrepreneurship Theory and Practice, 24(1), 29-45.

Brockhaus, R. H. (1980). Risk-taking Propensity of Entrepreneurs. Academy of Management Journal, 23, 509-520.

Brown, T., Davidsson, P., \& Wiklund, J. (2001). An operationalization of Stevenson's conceptualization of entrepreneurship as opportunity based behavior. Strategic Management Journal, 22(10), 953-968.

Burdett, J. O. (1998). Forty things every manager should know about coaching. Journal of Management Development, 17(2), 142-152.

Burgelman, R. A. (1984). Designs for corporate entrepreneurship in established firms. California Management Review, 26(3), 155-166.

Busenitz, L. W., \& Barney, J. B. (1997). Differences between entrepreneurs and managers in large organizations: Biases and heuristics in strategic decision making. Journal of Business Venturing, 12 (1), 9-30.

Carmines, E. G., \& Zeller, R. A. (1979). Reliability and validity assessment. London: Sages.

Chen, C., Green, P., \& Crick, A. (1998). Does entrepreneurial self-efficacy distinguish entrepreneurs from managers? Journal of Business Venturing, 13, 295-316. 
Chen, G., et al. (2001). Validation of a new general self-efficacy scale. Organizational Researsch Methods, 4(1), 62-83.

Choi, J. N., Price, R., \& Vinokur, A. (2003). Self-efficacy in groups: effects of diversity, leadership, and group climate. Journal of Organizational Behavior, 24, 357-372.

Covin, J. G., \& Slevin, D. (1991). A conceptual model of entrepreneurship as firm behavior. Entrepreneurship Theory and Practice, 16(1), 7-25.

Damanpour, F. (1991). Organizational innovation: A meta-analysis of effects of determinants and moderators. Academy of Management Journal, 34, 555-590.

Dess, G. G., Ireland, R. D., Zahra, S. A., Floyd, S. W., Janney, J. J., \& Lane, P. J. (2003). Emerging issues in corporate entrepreneurship. Journal of Management, 29(3), 351-378.

Echols, A. E., \& Neck, C. P. (1998). The impact of behaviors and structure on corporate entrepreneurial success. Journal of Managerial Psychology, 13(1,2), 38-46.

Ellinger, A. D., \& Bostrom, R. P. (1999). Managerial coaching behaviors in learning organizations. Journal of Management Development, 18(9), 752.

Evered, E. D., \& Selman, J. C. (1989). Coaching and the art of management. Organizational Dynamics, $18(2), 16-32$.

Field, A. P. (2005). Discovering Statistics Using SPSS, Sage

Floyd, S. W., \& Lane, P. J. (2000). Strategizing throughout the organization: Managing strategic renewal and strategic role conflict. Academy of Management Review, 25, 154-177.

Gartner, W. (1985). A conceptual framework for describing the phenomenon of new venture creation. Academy of Management Review, 10, 696-706.

Gartner, W. B. (1988). Who is an entrepreneur? is the wrong question. American Journal of Small Business, 12(4), 11-32.

Gist, M. E., \& Mitchell, T. R. (1992). Self-efficacy: a theoretical analysis of its determinants en malleability. Academy of Management Review, 17, 183-211.

Granovetter, M. (1973). The strength of weak ties. American Journal of Sociolog, 78, 1360-1380.

Greene, J., \& Grant, A. (2003). Solution-Focused Coaching. Harlow: Pearson Education.

Guth, W. D., \& Ginsberg, A. (1990). Guest editors' introduction: corporate entrepreneurship. Strategic Management Journal, 11(5), 5-15, Special Issue.

Hargrove, R. (1995). Masterful Coaching. San Diego, CA: Pfeiffer.

Hayton, J. C. (2005). Promoting corporate entrepreneurship through human resource management practices: a review of empirical research. Human Resource Management Review, 15, $21-41$.

Hudson, F. M. (1999). The Handbook of Coaching. San Francisco, CA: Josey-Bass.

Kanter, R. M. (1985). Supporting innovation and venture development in established companies. Journal of Business Venturing, 1, 47-60.

Kelley, D., et al. (2005). Corporate entrepreneurship through radical innovation: key organization and initiative level mechanism. In T. Elfring (Ed.) Corporate entrepreneurship and venturing (pp. 23-48). New York: Springer Science.

Kilburg, R. R. (1996). Towards a conceptual understanding and definition of executive coaching. Consulting Psychology Journal: Practise and Research, 48(2), 134-144.

Kirzner, I. (1979). Perception, Opportunity, and Profit. Chicago: University of Chicago Press.

Kirzner, I. (1997). Entrepreneurial discovery and the competitive market process: an Austrian approach. Journal of Economic Literature, 35, 60-85.

Krueger, N. F., \& Brazeal, D. (1994). Entrepreneurial potential and potential entrepreneurs. Entrepreneurship: Theory and Practise, Spring, 91-104.

Kuratko, D. F., \& Hodgetts, R. M. (2003). Entrepreneurship: theory, process and practise. Forth Worth: Dryden.

Kuratko, D. F., Hornsby, J. S., \& Goldsby, M. G. (2004). Sustaining corporate entrepreneurship: modelling perceived implementation and outcome comparisons at organizational and individual levels. International Journal of Entrepreneurship and Innovation, 5(2), 77-90.

Lumpkin, G. T., \& Dess, G. G. (1996). Clarifying the entrepreneurial orientation construct and linking it to performance. Academy of Management Review, 21(1), 135-172.

Lyon, D., Lumpkin, G., \& Dess, G. (2000). Enhancing entrepreneurial orientation research: operationalizing and measuring a key strategic decision-making process. Journal of Management, 26(5), $1055-1085$.

Mair, J. (2005). Entrepreneurial behaviour in a large traditional firm: exploring key drivers. In T. Elfring (Ed.) Corporate entrepreneurship and venturing (pp. 49-72). New York: Springer Science.

Malone, J. W. (2001). Shining a new light on organizational change: improving self-efficacy through coaching. Organization Development Journal, 19(2), 27-36. 
McClelland, D. C. (1961). The achieving society. Princeton, NJ: Van Nostrand.

McShane, S. L., \& Von Glinow, M. A. (2003). Organizational behavior. New York: McGraw-Hill.

Miller, D. (1983). Entrepreneurship correlates in three types of firms. Management Science, 29, 770-791.

Millward Brown (2005) Survey, Amsterdam.

Parsloe, E., \& Wray, M. (2000). Coaching and mentoring. London: Kogan Page.

Popper, M., \& Lipshitz, R. (1992). Coaching on leadership. Leadership \& Organization Development Journal, 13(7), 15-18.

Schumpeter, J. (1934). Capitalism, socialism and democracy. New York: Harper \& Row.

Segal-Horn, S. (Ed.) (1998). The strategy reader. Milton Keynes: The Open University/Blackwell.

Shane, S., \& Venkataraman, S. (2000). The promise of entrepreneurship as a field of research. Academy of Management Review, 25, 217-226.

Shook, C. L., Priem, R., \& McGee, J. E. (2003). Venture creation and the enterprising individual: A review and synthesis. Journal of Management, 29(3), 379-400.

Stajkovic, A. D., \& Luthans, F. (1998). Self-efficacy and work-related performance: a meta-analysis. Psychological Bulletin, 124(2), 240-261.

Stevenson, H. H., \& Jarillo, C. (1990). A paradigm of entrepreneurship: entrepreneurial management. Strategic Management Journal, 11, 17-27.

Stopford, J., \& Baden-Fuller, C. (1994). Creating corporate entrepreneurship. Strategic Management Journal, 15, 521-536.

Stull, M., \& Singh, J. (2005). Intrapreneurship in nonprofit organizations: examining the factors that facilitate entrepreneurial behaviour among employees. Working Paper Case Western Reserve University

Witherspoon, R., \& White, R. (1996). Executive coaching: what's in it for you? Training and Development, March, 14-15.

Wood, R., \& Bandura, A. (1989). Social cognitive theory of organizational management. Academy of Management Review, 14(3), 361-384.

Zahra, S. (1991). Predictors and financial outcomes of corporate entrepreneurship: An exploratory study. Journal of Business Venturing, 6(4), 259-285.

Zahra, S., \& Covin, J. G. (1995). Contextual influences on the corporate entrepreneurship-performance relationship: a longitudinal analysis. Journal of Business Venturing, 10(1), 43-58.

Zahra, S., Nielsen, A. P., \& Bogner, W. C. (1999a). Corporate entrepreneurship, knowledge and competence development. Entrepreneurship Theory and Practice, 24(1), 169-189.

Zahra, S., Kuratko, D. F., \& Jennings, D. F. (1999b). Guest editorial: entrepreneurship and the acquisition of dynamic organizational capabilities. Entrepreneurship Theory and Practice, 24(1), 5-10.

Zeus, P., \& Skiffington, S. M. (2002). The complete guide to coaching at work. New York: McGraw-Hill. 